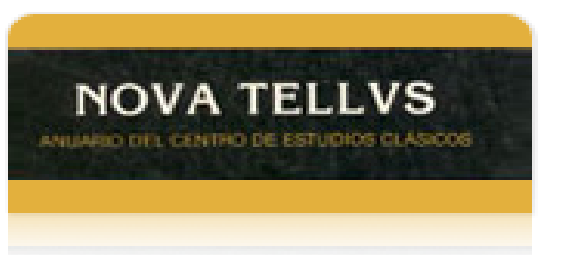

Nova Tellus

ISSN: 0185-3058

novatelu@servidor.unam.mx

Centro de Estudios Clásicos México

Rodríguez Maldonado, Marysol Alhim Imagen de Ártemis en el Himno III de Calímaco Nova Tellus, vol. 31, núm. 2, 2014, pp. 159-184

Centro de Estudios Clásicos

Distrito Federal, México

Disponible en: http://www.redalyc.org/articulo.oa?id=59137773007

- Cómo citar el artículo

- Número completo

- Más información del artículo

- Página de la revista en redalyc.org

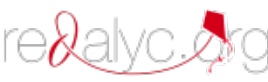

Sistema de Información Científica

Red de Revistas Científicas de América Latina, el Caribe, España y Portugal Proyecto académico sin fines de lucro, desarrollado bajo la iniciativa de acceso abierto 


\title{
Imagen de Ártemis en el Himno III de Calímaco'
}

The Image of Artemis in Callimachus' Hymn III

\author{
Marysol Alhim RodRÍGUEZ MALDONADO \\ Universidad Nacional Autónoma de México
}

alhimrm@yahoo.es

\begin{abstract}
RESUMEN: En este artículo ofrezco un análisis de las características con que Calímaco dotó a Ártemis en su Himno III, y a partir de él sugiero y defiendo la hipótesis de que el poeta presenta en su versión mítica un desarrollo o evolución de la diosa que la lleva de un estado de raîs a una transformación en

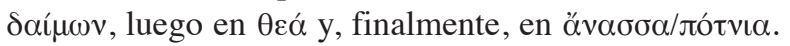

ABSTRACT: This paper comprehends an analysis of the characteristics given by Callimachus to Artemis in his Hymn III. On that account, I suggest and uphold the hypothesis that the poet presents in his mythical version a development or evolution of the goddess which leads her from one state of Jais to a transformation into a $\delta \alpha \hat{\prime} \mu \omega v$, subsequently into a $\theta \varepsilon \alpha ́$ and finally into an

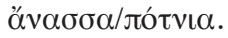

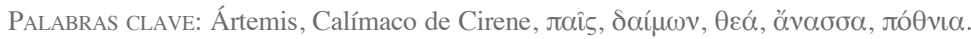

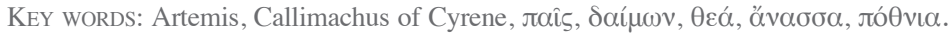

RECIBIDO: 6 de diciembre de 2013 • ACEPTADO: 11 de abril de 2014.

\section{Introducción ${ }^{2}$}

Calímaco, erudito de la literatura griega en sus diversos géneros y enamorado del patrimonio cultural griego antiguo, se afanó en recopilar este último, asimilarlo, recrearlo y transmitirlo, por lo que en sus Himnos - herederos directos de los Himnos homéricos - refleja su vasto conocimiento con respecto a las versiones más comunes de la mitología griega, a tal grado que asegura que no canta nada que no esté atestiguado, pues, como asevera en el verso 56 de El baño de Palas, "el relato no es suyo, sino de otros". Sin embargo, gustaba de darle su propio "estilo" a los mitos ya existentes para que éstos se adaptasen a su época, así como de escoger temas no muy conocidos o de manipular las versiones tradicionales para que, además de provocar asombro, pareciese

${ }^{1}$ Este artículo es resultado de un trabajo homónimo más extenso realizado como tesis de Licenciatura en Letras Clásicas en 2010.

${ }^{2}$ Las traducciones del himno en cuestión están tomadas de la edición de la Bibliotheca Scriptorum Graecorum et Romanorum Mexicana, a menos que se indique lo contrario. 
que no fueron modificadas por él. Esta manipulación mítica no se ciñe únicamente a los hechos referidos en el relato, sino que se extiende a los caracteres de los dioses que participan en él, los cuales, sin dejar de ser aquellos olímpicos respetados desde antiguo, al momento de aparecer en "mitos contados por Calímaco" se convierten en deidades más populares, más "terrenales".

Debido a que el peculiar canto de alabanza que el poeta escribe en honor de Ártemis es de suma importancia para los estudios mitológicos, no sólo por recopilar y transmitir la tradición mítica antigua, sino por ser evidencia de su evolución, presento aquí un análisis del carácter con que Calímaco dotó a la diosa - esto es, tratar su origen, características, nombres diversos, honores o prerrogativas, habilidades o competencias, cultos y distintas versiones míticas que se refieren en el himno tratado-, ciñéndome al hecho de que este autor da un puesto preponderante a la naturaleza infantil de Ártemis, y, a partir de su infancia, narra su

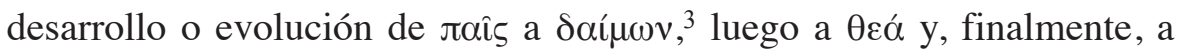

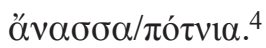

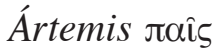

La primera parte del himno está estructurada por el carácter infantil de la deidad y las relaciones que ésta entabla con Zeus, Apolo y Hera. Sin embargo, me limitaré a presentar el vínculo de Ártemis con Zeus, su padre, por considerarlo de mayor peso dentro de la evolución de la diosa.

En los versos 4-6, ella se sienta en las rodillas de su padre ${ }^{5}$ y lo llama ó $\pi \tau \alpha,{ }^{6}$ lo cual denota una relación de respeto y afecto entre ellos.

De igual forma, también destaca la relación de edad que Calímaco enfatiza y que se vinculará con la virginidad de la diosa. El vocablo raîs se refiere tanto a un hijo o a una hija como a alguien de corta edad o con

3 "Simple poder divino", "divinidad menor inferior a los dioses", mientras que $\theta \varepsilon \alpha$ denota un dios en persona, cf. Liddell 1940, s. v.

4 "Reina", "señora", cf. Liddell 1940, s. v.

5 A pesar de la utilización del término $\gamma$ ovî $\alpha$ en el verso 5, que alude al padre únicamente en términos biológicos: "el que engendra", "el progenitor", cf. Liddell 1940, s. v. Escena semejante a Hom. Il. 21.506-514 y 1.512-513, 557.

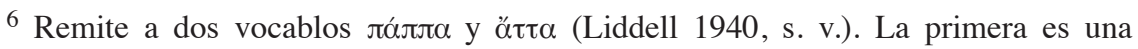
palabra de vocabulario infantil; la segunda, una forma de saludo para los mayores. 


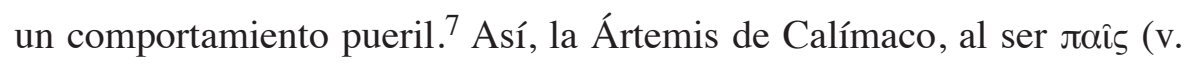
26), no es una adolescente, sino una niña; más aún, el término se vincula con el participio xov@í̧́ov $\sigma \alpha^{8}$ del verso 5 , y así se entiende ya desde Homero, 9 como una "soltera", una doncella "casadera".

Tomando como punto de partida un pasaje homérico (Il. 21.505-508) en el que Ártemis, castigada por su madrastra, corre a refugiarse con su "papá" y llora y tiembla como una pequeña - por lo que el padre no puede dejar de consolarla y a la vez de reír, pues la diosa-niña está haciendo "berrinche" - , es posible observar que, también en Calímaco,

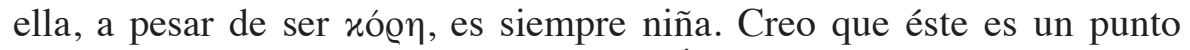
central en el himno: la caracterización de Ártemis como "doncella eterna", la cual permanece en un estado "intermedio" entre dichas etapas de la vida femenina (niña y doncella casadera), hecho que devela su carácter como protectora de los niños y diosa de la transición de la edad infantil a la madurez, a la que se le ofrecen los "juguetes" de las niñas para que éstas puedan pasar a ser esposas. Asimismo, se enfatiza el aspecto liminar de la deidad, no sólo en el ámbito geográfico, sino también en los ciclos de la vida.

Ártemis mantiene así una dependencia con Zeus, hecho que se comprueba en los versos 4-40, donde ella hace numerosas peticiones y su padre se las otorga, en contraste con los versos 72-86, donde Ártemis, lejos de su progenitor, ya no se comporta como $\pi \alpha i ̂ s$.

En los versos 6-32 se habla de un suceso que marca fuertemente el temperamento caprichoso de la diosa y la relación mutua, hasta cierto punto dependiente, entre la hija "caprichosa" y el padre "consentidor". Ártemis se deleita pidiendo atributos, y Zeus, encargado de definir los ámbitos de poder de los dioses,$^{10}$ se deleita en concedérselos, incluso sin importarle la cólera que Hera pueda desatar por este hecho (vv. 2930). Como es bien sabido, en la tradición mítica, la única hija favorita y tomada en cuenta es Atenea, pues su nacimiento es paterno-filial, tiene un vínculo de poderes o semejanzas con su progenitor y es la perfección emanada únicamente de él por no estar contaminada con

\footnotetext{
${ }^{7}$ Cf. Liddell 1940, s. v.

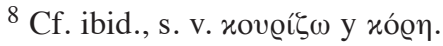

${ }^{9}$ Hom. Il. 16.7; también Aristoph. Lys. 595 y ss.

${ }^{10}$ Cf. Hom. Il. 5.426-430.
} 
lo femenino. ${ }^{11}$ Así, según los cánones de la sociedad patriarcal griega, Atenea es superior (es la preferida) a una diosa femenina como lo es Ártemis. No obstante, y a pesar de que Calímaco caracteriza a ésta como "consentida", y no como la "preferida", pareciera que el poeta deja de lado la tradicional conducta patriarcal y, al hacer que Zeus esté orgulloso de ella, trata de darle valor a la hija (Ártemis femenina) por sobre el hijo, representado en esta ecuación por la masculina Atenea.

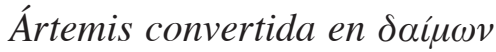

Obtención de su escolta de Oceánides

En el himno, Ártemis atraviesa por un proceso de crecimiento para llegar a formar parte de los Olímpicos; sin embargo, esta evolución no se da de manera abrupta, sino de modo gradual y en diferentes etapas. La

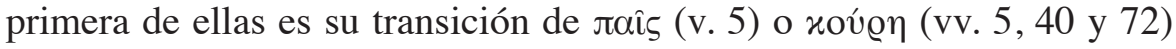
a $\delta \alpha i ́ \mu \omega v$ (como se le evoca en el v. 86), es decir, el momento en el que comienza a adquirir su fuerza o poder divino. Dicha etapa de cambio está emblematizada primero por la adquisición de su escolta de Oceánides (vv. 13-14, 42-45).

Es importante que Calímaco especifique que ellas sean "niñas de nueve años sin faja". Recordemos que los niños en Grecia llevaban la túnica holgada y sin cinturón, por lo que esta alusión refuerza el carácter infantil de las ninfas solicitadas. Ahora, el hecho de que sean niñas pequeñas anuncia el patronazgo que esta diosa tendrá sobre las jovencitas, pues, a los nueve años de edad, las niñas eran consagradas al servicio de Ártemis, que las protegía hasta que eran núbiles; además, la diosa, en un proceso de evolución, necesita de un séquito adecuado que haga que comience a trascender su propia niñez, pues ahora ella será la líder y, de alguna manera, la responsable de aquel grupo coetáneo.

Obtención de arco y flechas

Después de obtener su coro de Oceánides, Ártemis va en busca de sus armas: arco, flechas y carcaj (v. 8), que serán forjadas por los Cíclopes

${ }^{11}$ Cf. p. e. ibid. 8.373, 384, 426-427; 9.35. 
(vv. 8-10, 81-83). En esta parte Calímaco hace una peculiar especificación: lo que quiere la diosa es un "arco cidonio" (v. 81), es decir, cretense, debido acaso a que la arquería en el mundo griego fue ejercida especialmente por los cretenses, ${ }^{12}$ quienes tenían fama de ser buenos arqueros, o a una marcada relación de la diosa con la isla.

En Grecia, al arco se le consideraba un arma afeminada, propia de cobardes y bárbaros. ${ }^{13}$ Sin embargo, en el mundo divino, esta arma adquiere una connotación totalmente diferente a la que se le dio entre los mortales. En manos de un dios, ya no simboliza cobardía o afeminamiento, sino que es emblema del respeto o del terror que se le profesa a la deidad..$^{14}$

Y es así como, con estos atributos, Calímaco le confiere a la diosa un crecimiento y la pauta para proyectar su posterior y principal poder en el mundo, como diosa de la caza, y, al caracterizarla con la valentía suficiente para encarar a los Cíclopes (vv. 9-10, 81-83) y convencerlos de elaborar sus armas, hace que Ártemis se marche, ya no como $\pi \alpha i ̂ \varsigma$

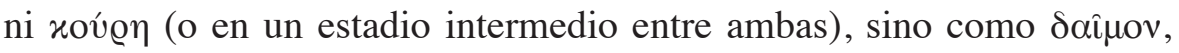
como una divinidad en potencia.

\section{Evolución a $\theta \varepsilon \alpha ́$}

Ártemis $\pi \alpha \varrho \theta \varepsilon v i ́ \alpha$

Calímaco, siguiendo la tradición, ${ }^{15}$ presenta una Ártemis eternamente virgen, atributo que ella pide desde niña (v. 6) y que se concreta en el himno cuando el poeta la evoca con éste como su primer epíteto: Ártemis $\pi \alpha \varrho \theta \varepsilon v i ́ \alpha$ (v. 110).

El vocablo $\pi \alpha \varrho \theta \varepsilon ́ v o \varsigma,{ }^{16}$ en cuanto al ámbito femenino, tiene tres acepciones principales: 1) Hace referencia a la virginidad física; 2) designa a las jovencitas que no han contraído matrimonio y, por lo tanto, no han sido madres, y 3) denomina a toda mujer "soltera", "sin marido",

12 Cf. p. e. Plat. Leg. 795b-c, 813d-e, 834d.

13 Cf. p. e. Hom. Il. 9.385-390, 13.710-723.

14 Cf. p. e. H. Hom. XXVII, 1-18; H. Hom. III, 1-5; Hom. Il. 24.600-613; Od. 11.170$173,15.403-412$.

15 Cf. p. e. H. Hom. V, 15-20; Eur. Hipp. 13-17, 107, 1301-1303.

${ }^{16}$ Cf. Liddell 1940, s. v. 
independientemente de su edad y de si ha tenido o no relaciones sexuales.

Partiendo de estos significados, y con base en el hecho de que Calímaco jamás especifica el motivo por el cual la diosa elige la virginidad eterna, podemos inferir que la pide para no pasar, igual que su madre, por los terribles dolores de parto ${ }^{17}$ o para ser "soltera" y no estar unida o sometida a varón alguno. La libertad que le confiere a Ártemis su soltería relaciona su naturaleza virginal con las regiones despobladas y lejanas que están "libres" de toda acción del hombre (prados, bosques y montes); ${ }^{18}$ tanto la naturaleza salvaje como la diosa son inaccesibles. Siguiendo esta línea de asociación, Ártemis $\pi \alpha \varrho \theta \varepsilon v i ́ \alpha$ tiene a su cuidado a las jovencitas prepubescentes que se encuentran entre los 9 y 12 años. La diosa las protege mientras se encuentran en estado "salvaje" y no están integradas a la sociedad ni sujetas al matrimonio, pero también toma a su cargo su formación, sus cambios biológicos y su transición de la infancia a la madurez para asegurarse que posteriormente formen parte de la sociedad civilizadora mediante el matrimonio, cuando asumen la situación de esposas y madres. ${ }^{19}$

Ártemis, como diosa, puede instalarse en la virginidad de manera definitiva sin que esto signifique alejamiento o carencia de feminidad; así, su virginidad no es como la de la guerrera Atenea, hostil y ajena al sexo y sus placeres, sino una virginidad agreste, provocadora, erótica, que seduce a los hombres. ${ }^{20}$ Es tan atrayente por no estar manifiesta ni revelada, que parece invitar a la violación, pero esta deidad castiga severamente a los que atentan contra ella o contra sus allegados, como lo apunta el segundo epíteto que le confiere el himno, Ticionicida, que alude a la muerte del gigante Ticio cuando éste intentó violar a Leto, o como lo revelan los versos 264-265 del himno, en los que se evoca el mito de la muerte de Orión y el de la de los Alóadas, por aspirar todos ellos a unirse con la diosa. ${ }^{21}$

17 Cf. p. e. H. Hom. III, 91-95; Apollod. 1.21.

18 Cf. p. e. Eur. Hipp. 73-89.

${ }^{19}$ Cf. Gimbutas 1991, pp. 230-231; Kirk 1992, p. 189; Aristoph. Lys. 645.

${ }^{20}$ Cf. p. e. Hom. Il. 16.180-186; Plut. Thes. 31.

21 Para el mito de Ticio, véase Apollod. 1.4.1, y para Orión, Apollod. 1.4.3, y Eratosth. Cat., 32. Para el pasaje de los Alóadas, Apollod. 1.7.4, y Hom. Od. 11.305-310. 


\section{Perros de caza}

A pesar de ser parte importante dentro del ejercicio de la caza que practica Ártemis, Calímaco no abunda en la información y descripción de su jauría (vv. 87-98), formada por hembras y machos; sin embargo, podemos inferir o imaginar la apariencia de estos animales basándonos en los pocos adjetivos que brinda el poeta, en representaciones de Ártemis y escenas de caza en la cerámica griega, ${ }^{22}$ en la descripción de los cánidos hecha por Jenofonte (Cyn. 4. 1-2,7), y en algunos perros de caza actuales originarios de Grecia como el Hellenikos Ichnilatis y el Kritikos Ichnilatis, razas que datan de hace miles de años y son descendientes del antiquísimo Lakonikoi. ${ }^{23}$

Ahora bien, Calímaco habla de la superioridad de las hembras no en cuanto a la edad, sino a la velocidad, pues las califica como $\theta$ óo-

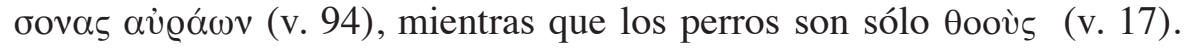
Luego entonces, encontramos en los adjetivos que les confiere el poeta una revaloración, como en el caso de la ya mencionada revaloración de la hija (Ártemis) sobre el hijo (Atenea), incluso una superioridad de lo femenino respecto a lo masculino.

Los canes, como acompañantes de Ártemis en el himno, tienen un

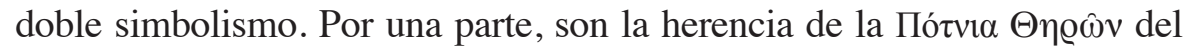
paleolítico o de la Gran Diosa del Neolítico. Así asocian a dicha deidad con la naturaleza (tierra, mar, cielo), la fecundidad y los ciclos de la vida (además con los ciclos lunares ${ }^{24}$ ). Por otra parte, la obtención de los cánidos de Ártemis puede ser un medio o significado de la epifanía de la diosa en su próximo poder como patrona de la caza, pues, con ellos y su arco, la ahora $\theta \varepsilon \alpha ́$, "diosa", desarrollará esta actividad.

Es menester anotar brevemente que Calímaco nunca menciona que los perros porten aditamentos como collares, correas y ventreras, comunes

${ }^{22}$ Véase p. e. Aristot. HA 607a; "La muerte de Acteón”, en una crátera de campana atribuida al Pintor de Pan (470 a. C.); el mismo tema en una crátera del Pintor de los Sátiros Velludos (460-440 a. C.), en una crátera de campana del Pintor de Licaón (440 a. C.), en un esquifos apulio (400-350 a. C.), o en un nestoris del Pintor de las Coéforas (350-340 a. C.); "Un cazador y su perro", en un oinócoe (550-530 a. C.); "escena de caza", en el friso inferior de una hidria caeretana con la representación de Heracles dando muerte a Busiris (520-510 a. C.). Cf. Villard 1956, pp. 12-16, y Boardman 1974, pp. 25-30.

${ }^{23}$ Cf. E-canina: http://www.e-canina.com.ar; "Greek Dog Breeds".

${ }^{24}$ Cf. Gimbutas 1991, p. 195. 
desde tiempos helenos, como atestigua Jenofonte (Cyn. 2.4; 6.1; 6.11; $9.7 ; 9.14)$, acaso para aludir a la doble naturaleza del animal, doméstico y "libre", la cual también es parte de la diosa. En este punto ya es bastante claro que Ártemis, con su naturaleza virginal, denota un estado de "libertad y salvajismo" - que se reforzará cuando desempeñe, por primera vez en el himno, su prerrogativa como patrona de la caza y de los animales - ; posteriormente, en el desenvolvimiento y pleno ejercicio

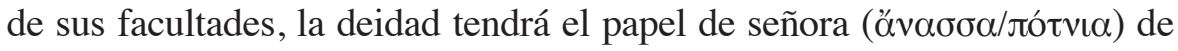
ciudades y de encargada de preparar a las chicas para el matrimonio, por lo que, en cierto sentido, la civilidad (domesticación) entrará en su ámbito de poder.

Cuadriga cornuda

Como primicia de la caza, Ártemis atrapa en las faldas del monte Parrasio, a orillas del Anauro arcadio, cuatro de las cinco famosas ciervas que poseían cuernos de oro y cuyo tamaño superaba al de un toro (vv. 98100, 102, 104-105, 112).

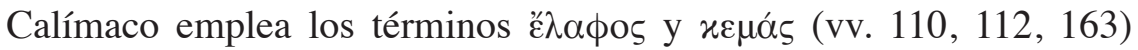
para designar a estos animales. Así se entiende que eran cervi elaphi, ${ }^{25}$ los típicos ciervos rojos propios de las zonas montañosas de Europa, Asia y África del Norte. Se entendería también que eran muy jóvenes, pero ya no unas cervatillas, pues el vocablo $x \varepsilon \mu \alpha{ }^{26}{ }^{26}$ designa a un ciervo o una cierva joven, pero en un estado intermedio entre un veß@ós (cervatillo) y un é $\lambda \alpha \phi o \varsigma$ (ciervo adulto). La referencia a la "edad" de las ciervas es interesante, pues, en mi opinión, concuerda con la línea de crecimiento de la diosa que el autor ha planteado en el himno. En estos momentos, Ártemis ha madurado tanto en edad como en poder divino, por lo que es coherente que esto se refleje en sus animales consagrados.

Existen algunas explicaciones modernas, que no abordaré aquí, sobre el gran tamaño de las ciervas y la asignación mítica a éstas de cornamenta (vv. 102, 113), ya que las hembras de estos animales no tienen cuernos. Por ahora baste decir que a lo largo de la literatura griega hay diversos testimonios que hablan propiamente de ciervas

25 Cf. Liddell 1940, s. v.

26 Cf. ibid., s. v. 
que presentan cuernos. ${ }^{27}$ Además, existe un sello minoico procedente de Zacros, que retrata un ciervo bailarín con una gran cornamenta, y grandes senos, lo que sugiere que es hembra. ${ }^{28}$ Igualmente, Marija Gimbutas dice que desde el periodo Protogeométrico (925-900 a. C.) existen en Grecia representaciones de venados con cuernos y decorados con cuadrículas o redes, las cuales hacen pensar que éstas son hembras, pues el simbolismo de la red está asociado con la vida y el parto. ${ }^{29}$

Ya sea que se trate de un invento del imaginario griego, de una excepción de la naturaleza o que fuera otro tipo de animal, el hecho de que Calímaco optase aquí por seguir la tradición de las ciervas cornadas tendría sentido, pues, según Chevalier, la cierva evoca generalmente la feminidad en estado primitivo e instintivo, no plenamente revelado - que remitiría a la virginidad de Ártemis - y es, en esencia, un símbolo de la Madre Nutricia al cuidado de los niños. Por lo que concierne a su cornamenta, el mismo Chevalier dice que ésta, por renovarse periódicamente, se compara con el árbol de la vida - representado desde el Neolítico en relación con la Gran diosa-, simbolizando la fecundidad, los ritmos de crecimiento, los comienzos de la vida y los ciclos de la luna. Así, la asociación de la cierva hembra con los cuernos propios del macho representa, por una parte, la feminidad salvaje, la creación periódica, la vida inagotable y la fecundidad en todo su esplendor, simbolizando así, mediante el uso de elementos masculinos para reforzar los femeninos, la epifanía de Ártemis como diosa protectora de los partos difíciles, ${ }^{30}$ de los niños y jóvenes (incluyendo las crías de los animales); por otra parte, apoyaría la revaloración (o intento de obtener la superioridad) que, a través del himno, hace Calímaco de lo femenino respecto a lo masculino.

${ }^{27}$ Aristot. IA 4.538b18; Ael. NA. 7.39; 9.40.

${ }^{28}$ Gimbutas 2001, p. 115.

${ }^{29}$ Y no sólo en Grecia se han dado estas representaciones, pues, desde tiempos antiguos, en el norte de Asia (recordemos que a Ártemis se le ha atribuido un origen asiánico), por ejemplo, se creía en la existencia de una cierva cornada y preñada que era la dadora de toda vida. Cf. Kirk 1992, p. 210; Duby 1991, p. 54; Gimbutas 2001, p. 113.

30 Chevalier 1993, s. v. cierva. Gimbutas (2001, pp. 113, 115) habla de representaciones de ciervas cornadas que hacen alusión a la maternidad y apunta que el ciervo rojo o venado es, en varias culturas, el animal sagrado de la diosa de los partos. 
Diosa del mundo salvaje y de la caza

El hecho de que Ártemis sea patrona de los animales y cazadora por excelencia procede de una larga tradición,,$^{31}$ por lo que, en el himno, su principal prerrogativa al convertirse en $\theta \varepsilon \alpha ́$ es su relación con lo salvaje e incivilizado, con la vida y con la caza.

Calímaco especifica que Ártemis, de niña, pide a su padre que le otorgue todos los montes para vivir en ellos alejada de las ciudades (vv. 17-20). En los tres primeros versos del himno, se habla acerca del solaz ( $\dot{\varepsilon} \psi(\alpha ́ \sigma \theta \alpha \iota)$ que encuentra la diosa en dichos lugares, y posteriormente se nombran cuatro montes importantes dedicados a ella: Leuco (vv. 4041), Parrasio (vv. 98-106), Hemo (vv. 114-115) y Taigeto (v. 188).

Atendiendo a la geografía de los montes señalados por el poeta, puede inferirse que éstos son una síntesis o que simbolizan el poderío de la diosa en las regiones de Creta, ${ }^{32}$ Arcadia, Tracia y el Peloponeso.

En cuanto a la vestimenta que Ártemis usará en el ejercicio de la caza, Calímaco especifica que ella porta un quitón dórico con un cinto de oro (vv. 11-12, 110-111, 225). Por la información del himno, lo más probable es que el quitón de la diosa es corto o tal vez se recogía el quitón largo, como el de la Diana de Versalles, lo que le facilitaría la empresa de cazar, pues deja las piernas libres y sin estorbo para poder correr. Sobre el calzado que porta la diosa, el poeta utiliza el término

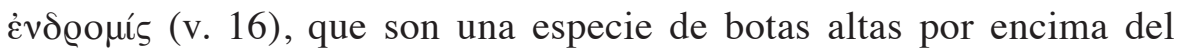
tobillo o más arriba usadas por los cazadores y por los corredores. ${ }^{33}$

Parece entonces que la descripción de las vestiduras tiene la finalidad de definir a Ártemis como cazadora y una deidad de movimientos libres, aspecto que se liga perfectamente con el tema de la libertad y virginidad.

Como diosa de los montes y de la caza - la cual es una forma de civilizar, de domar lo salvaje, que anticiparía su posterior relación con las

${ }^{31}$ Cf. p. e. Hom. Il. 5.51 ss. y 21.470 ss.; Od. 6.102 ss.; H. Hom. XXVII; Aesch. Ag. $40 \mathrm{ss}$.

${ }^{32}$ La mención del monte Leuco anuncia la relación que se verá más adelante entre

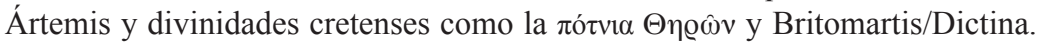

33 Cf. Liddell 1940, s. v. El escolio al verso hace la precisión con el vocablo نंлоðท́ $\mu \alpha \tau$ (Scholl. ad Call. H. III, 16), un tipo de sandalia o media bota que se ataba con correas (Liddell 1940, s. v.). 
ciudades, los límites, e incluso con las jovencitas preparándose para el matrimonio-, lo sería también del mundo salvaje en todos sus planos: animales, ${ }^{34}$ plantas, tierras no cultivadas (también jovencitos no integrados aún a la sociedad), etcétera; es por ello que algunos estudiosos la

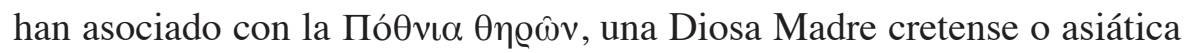
comparada con Cibeles. ${ }^{35}$

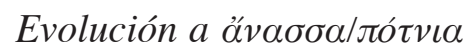

Calímaco no detiene la evolución de Ártemis en el estadio de $\theta \varepsilon \alpha ́$, sino

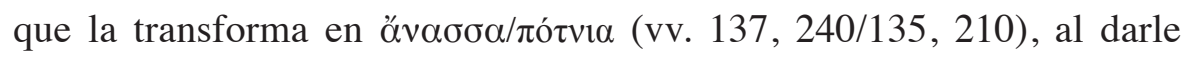
un nuevo significado a sus atributos, con énfasis en su intervención en otros dominios más allá de los montes y la caza, al trazar la importancia de su traslado de la tierra al Olimpo y hablar de su culto en regiones orientales.

La antorcha y el arco de plata, atributos lunares y de justicia

Además de arco y flechas, la diosa suele portar una antorcha o lumbrera hecha de pino y encendida con fuego divino producto de los rayos de Zeus (vv. 11, 116-118). Por este atributo se le suele denominar

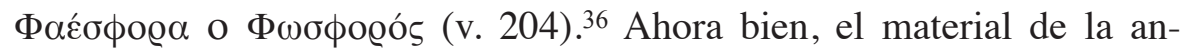
torcha podría aludir a que jamás se extingue, porque dicho árbol es un símbolo de inmortalidad, debido a que su follaje es perenne y su resina incorruptible. ${ }^{37}$

El atributo de la antorcha puede referirse a tres aspectos importantes de Ártemis: a la caza nocturna y a la luz que alumbra los caminos de

${ }^{34}$ Cf. p. e. Hom. Il. 5.51, 21.470; Od. 6.104.

35 Cf. Hom. Il. 21.470; Rose 1973, p. 116; Vernant 2001, pp. 22, 49-50; Ruipérez 1947 , p. 35.

36 Éste es un epíteto atribuido también a Hécate (Aristoph. Lys. 443; Eur. Hipp. 21). En la cerámica del siglo v es común la representación de Ártemis con antorchas en ambas manos (Soph. Trach. 214; Soph. OT 207; Paus. 9.19.6).

${ }^{37}$ Cf. Chevalier 1993, s. v. Respecto a la incorruptibilidad de la resina del pino, vale la pena recordar una de las variantes del mito de la ninfa Pitis: ésta era deseada por Pan, y un día, al acercársele el dios, la joven escapó y fue convertida en pino para que conservara su virginidad. Cf. Luc. DDeor. 22.4. 
noche, a la virginidad de la diosa y a lo relativo al parto, pues tal vez "portar la antorcha", "llevar la luz", tenga que ver con "dar a luz", que en el estricto sentido de esta deidad sería "ayudar a dar a luz"; 38 así quedaría reforzado su aspecto como protectora en los partos difíciles.

Ahora bien, el hecho de que los rayos de Zeus provean el fuego para la antorcha haría que la diosa compartiera la prerrogativa que el Cronida imparte mediante el rayo: la justicia y las leyes. Además, según la tradición, los reyes proceden de Zeus, ${ }^{39}$ es él quien les da su poder y la capacidad de impartir justicia y leyes, y, basándonos en esto, podemos decir que, al obtener la prerrogativa de justicia, en ese momento Ártemis se convierte en reina, en soberana, en óv $\alpha \sigma \sigma \alpha$.

En el himno se menciona que las armas de la diosa son de oro; sin embargo, en el verso 119, Calímaco cambia dicho material por la plata. Es sabido que este metal está en relación con la luna, con el principio femenino y, por su color y luminosidad, con la pureza,${ }^{40}$ que en el caso de Ártemis remitiría a su virginidad. Es así que, probablemente, se haga esta especificación para asociar a esta deidad con la diosa Luna y enfatizar su virginidad y feminidad.

En los versos 121-123, se alude a algún castigo que ella aplicó probablemente al pueblo de los tauros por practicar ritos sangrientos, ${ }^{41}$ aunque es extraño que Ártemis los castigue, pues a ella le ofrecían dichas prácticas. Esto es de suma importancia, porque hace pensar que el arco de plata tiene un significado más profundo que un simple emblema lunar y de virginidad o feminidad: es, al igual que la antorcha, un símbolo justiciero. Ahora, la impartición de la justicia no es exclusiva de Zeus, sino que es una prerrogativa que la diosa comparte, y que no es invento de Calímaco, ya que este poeta retoma lo dicho en el verso 20 del Himno homérico $V^{42}$ para volverla diosa de la justicia y así elevarla en dignidad, convertirla en soberana.

38 Cf. p. e. Antonino Liberal, Met. 15; Soph. OT 207. Según Rose (1973, p. 123), la antorcha es un atributo común de la fertilidad debido a que se asociaba la luz con la vida o con el nacimiento.

${ }^{39}$ Cf. p. e. Hes. Op. 36; Hom. Il. 1.238; 2.206, 9.99, 16.387; Call. H. I 79.

${ }^{40}$ Cf. Chevalier 1993, s. v.

${ }^{41}$ Cf. p. e. Eur. IT 35-42, 54, 72, 74, 245, 385, 405, 622, 685, 706, 776.

42 “A Ártemis le agrada la ciudad de varones justos" (traducción de Alberto Bernabé Pajares). 
Diosa de ciudades, caminos, islas y puertos

Para transformar a Ártemis en óv $\alpha \sigma \sigma \alpha / \pi o ́ \tau v ı \alpha$, el poeta extiende el poder de la diosa; ahora no sólo le pertenecen los montes, sino también ciudades, caminos, islas y puertos.

Dejando de lado la petición que su hija, cuando niña, le hace en los versos 18-20, Zeus decide otorgarle treinta póleis en las que se le venerará exclusivamente a ella, y otras tantas urbes e islas que la diosa tendrá que compartir, como se expresa en los versos 33-38, con otra deidad, probablemente su hermano Apolo.

Respecto a una de las ciudades que en el himno están bajo el patronazgo de la diosa, Halas Arafénides (v. 173), Calímaco hace la siguiente precisión: "[fue] tu residencia al llegar de Escitia cuando pusiste fin a los preceptos de los tauros" (vv. 173-174). Siguiendo la tradición marcada por Eurípides, pues, según éste, en Halas se encuentra un templo en el que, de acuerdo con el mito, Orestes depositó la imagen de la Ártemis táurica que trajo de Escitia, allí se celebra a la diosa como "Taurópola". Ahora bien, el poeta, al mencionar que Ártemis "prohibió los preceptos de los tauros", refiere que en el Ática se cambiaron los citados sacrificios sangrientos por unos en los que se "finge" degollar a un hombre, es decir, únicamente se araña con una espada su cuello para derramar unas cuantas gotas de sangre en honor de Ártemis Taurópola. ${ }^{43}$

También se le da importancia a la ciudad de Mileto, que en el himno es fundada bajo la dirección de la diosa (vv. 226-227). ${ }^{44}$ Así, Calímaco le confiere a Ártemis el carácter de deidad fundadora. Este patronazgo no es invento del poeta helenístico, pues, por ejemplo en Pausanias, ella muestra a los colonos el camino que deben seguir para llegar al lugar preciso en el que deben edificar la nueva ciudad. ${ }^{45}$

Además de patrona de ciudades, Zeus le asigna el dominio de los ca-

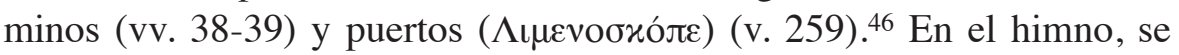
enlistan ciertos ríos y puertos de importancia para la diosa, y entre estas menciones, el autor intercala el siguiente relato: "a ti, Agamenón / te depo-

${ }^{43}$ Cf. Paus. 1.23.7, 33.1 , 3.16.7-11; Eur. IT 1449-1461; Burkert 2007, p. 205; Ruipérez 1947, p. 53; Kirk 1992, p. 189.

44 Cf. Paus. 3.22.12.

${ }^{45}$ Cf. Otto 1958 , p. 70.

${ }^{46}$ Cf. Apollon. 1.570, 2.927; Vernant 2001, p. 23; Paus. 2.7.6, 4.4.2, 31.3; Herrero Ingelmo, n. 21, en Paus. 4, p. 115. 
sitó en tu templo, el timón de su nave, / don del no poder navegar, cuando los vientos le ataste / mientras naves aqueas, para afligir ciudades de teucros, / navegaban, por Helena de Ramnunto enfurecidas" (vv. 228-232).

Con esta narración, Calímaco nos hacer pensar que Ártemis es diosa de los vientos y los mares, lo cual puede sustentarse con varias fuentes griegas. ${ }^{47}$ Esto tiene mucho sentido, pues, como protectora de los caminos terrestres, es evidente que su dominio se extienda a los caminos o rutas en el mar.

La custodia de ciudades, puertos y caminos le confiere a la deidad otro patronazgo importante: el de los límites, el cual comparte con Hécate y Hermes.$^{48}$ Un camino es propiamente una tierra hoyada donde se transita para ir de un lugar a otro; recorriéndolo se pueden transgredir los límites, es decir, acceder a mundos diferentes. Facilita la comunicación de opuestos, el comercio y el desplazamiento. Ártemis tiene patronazgo tanto en el mundo salvaje como en la ciudad, por tanto, preside los límites de esta última y la delimita. Un puerto es un lugar en la costa dispuesto para la seguridad de las naves, para las operaciones comerciales y militares, y para la pesca. Es el punto último donde convergen los diversos caminos o rutas marinas. Al igual que el camino, permite la comunicación y la transgresión de los límites territoriales y culturales.

\section{Su relación con el parto y las jóvenes}

En el himno, Ártemis protege a las mujeres y a las criaturas durante el parto, pero también puede darles muerte o hacer que éstas nazcan débiles, enfermas o deformes (vv. 126-128). ${ }^{49}$ Calímaco refiere que ella sólo

${ }^{47}$ Ruipérez (1947, p. 26) dice que la relación de Ártemis con el mar es de carácter tardío, siendo la primera mención la de la tragedia Agamenón de Esquilo (vv. 145-149, 191-204). Cf. Eur. Hipp. 228; IT 10-33, 783-786; IA 87-92, 1540-1589; Paus. 8.41.5; 1.38.6; 2.35.1; 8.14.15; Pind. P. 2.12; Apollod. Epit. 3.21; Aesch. Ag. 110 ss.; Apollod. Epit. 3.22 .

${ }^{48}$ Cf. Vernant 2001, pp. 23, 24, 30, 36, 38; Downing 1999, p. 197; Hes. Th. 938939; Apollod. 3.10.2; H. Hom. XIII; Paus. 2.19.6; Hom. Od. 24.1-14.

${ }^{49}$ La tradición de Ártemis partera la podemos encontrar, por ejemplo, en Apollod. 1.4.1 (aquí la diosa ayuda a Leto a parir a Apolo), en Aesch. Supp. 676 (se le pide que proteja a las mujeres en los partos) o en Eur. Hipp. 161-169 e IT 1090-1100 (se le invoca como "protectora de los partos"). Ártemis es considerada por Homero como "leona entre mujeres" (Il. 21.483-484), y éste le atribuye las muertes repentinas de mujeres, a quienes mata con sus "suaves saetas" (cf. Il. 6.428; Od. 11.172-173, 199; 15.410-411, 
aparecerá en las ciudades para realizar esta tarea, asignada por las Moiras desde el nacimiento de la diosa (vv. 20-26). Tal destino Ártemis lo atribuye a que Leto, su madre, no pasó por agudas penas al momento de darla a luz. ${ }^{50}$ Respecto a esto, no he podido encontrar ningún pasaje en el que se mencione que Leto parió sin dolor a su hija, por lo que es evidente que Calímaco modifica el mito o presenta un dato poco frecuente dentro de la tradición mítica para otorgarle mayor énfasis a la faceta de Ártemis como partera.

Es curioso notar, primero, que ella, siendo apenas una niña y eternamente virgen, es decir, alejada del matrimonio y exenta de dar a luz, tenga que participar de este hecho y, segundo, que Calímaco no sigue la tradición en la que la diosa ayudó a Leto a parir a Apolo; además, el poeta tampoco retoma el mito donde Ártemis y Apolo son gemelos. Según Vernant, tiene este patronazgo porque, el parto, acompañado de gritos, dolores, delirios, expresa a los griegos el aspecto salvaje y animal de la feminidad - aunque parezca que, en ese momento, la esposa al entregar un nuevo ciudadano a la polis está más integrada al mundo de la cultura - , aspecto presidido por Ártemis. Además, el alumbramiento es el fin de una prolongada maduración de las jóvenes bajo la vigilancia de la diosa y el inicio, para la nueva criatura, del proceso de la vida, de crecimiento, el cual también es responsabilidad de dicha diosa. ${ }^{51}$

$478-479 ; 18.202 ; 20.61,80)$. Pausanias, por su parte, refiere que ella puede hacer que las mujeres den a luz niños que han muerto antes del parto (8.23.7).

${ }^{50}$ Cf. Apollod. 1.4.1. La tradición de la ayudantía de Ártemis en el parto de Leto parece que no fue común dentro de la tradición griega, pero, para la época romana fue más normal. Hacia el año 400, Servio, el comentarista de Virgilio (Ecl. 4. 10, y A. 3. 73), ya hablaba de la participación de la diosa; alrededor del 350, Libanio (Or. 5.4) recuerda que Ártemis ayuda a su madre en el nacimiento de Apolo. En el siglo II, Apolodoro refiere el hecho (1.4.1). Cf. Tapia Zúñiga 1991, p. 11. Autores modernos especulan que ella, al ser considerada una divinidad extranjera, fue concebida desde su origen como protectora de los partos, y así fue asimilada o incluida en el panteón griego. Cf. Rose 1973, p. 115; Kirk 1992, p. 210; Duby 1991, p. 54.

${ }^{51}$ No todos los autores refieren que ella y Apolo son gemelos, o que nacieron en el mismo lugar: Apolodoro menciona que ambos hermanos nacieron en Delos, primero Ártemis y luego, con la ayuda de ésta, Apolo (1.4.1); Estrabón refiere que o nacieron ambos en Delos (10.5.2) o la diosa en Ortigia (14.2.20), pero ella no interviene en el parto; Nono de Panópolis los hace gemelos pero Ártemis no ayuda a su madre (27.259); El Orph. $H$. $X X X V$ dice que son gemelos, pero una nacida en Ortigia y el otro en Delos, y Ovidio dice que, en Delos, Leto "fue hecha madre de dos" (Met. 6.191-192) y más adelante reitera que en esa isla apoyándose en una palma y en el árbol de Palas parió gemelos (VI, 335-336). 
Ártemis no sólo protege a la madre y al embrión a lo largo del embarazo y durante el parto, sino que también se encarga del desarrollo físico del lactante y de los niños pequeños en general, patronazgo que ejerce con los humanos y con los animales. Y como diosa virgen, está especialmente asociada con las jovencitas prepubescentes, quienes se encuentran entre los 9 y 12 años. ${ }^{52}$ Ella se encarga de cuidarlas mientras se hallan en estado "salvaje", mientras no están integradas a la sociedad y sujetas al matrimonio, pero también toma a su cargo la formación de éstas, sus cambios biológicos y su transición de la infancia a la madurez, para asegurarse que posteriormente se integren a la sociedad civilizada mediante el matrimonio, ${ }^{53}$ cuando asumen la situación de esposas y madres. Es de suma importancia destacar que Calímaco presenta a Ártemis como protectora de los partos y de las jovencitas, pero no hace ninguna mención acerca de que también tenga bajo su cuidado a los jóvenes varones, ${ }^{54}$ acaso para tratar de dar un poco de superioridad a la mujer con respecto al varón.

Las más de las veces, cada hermano nace en un lugar distinto y no se menciona que la diosa haya asistido en el parto a Leto: En el Himno homérico III, Leto da a luz a Apolo en Delos y a Ártemis en Ortigia y quien la auxilia es Ilitía; en el Himno homérico XXVII sólo se dice que son hermanos carnales, pero nada más; Pausanias dice que Ilitía vino del país de los hiperbóreos a Delos para asistir a Leto (1.18.5), en el Himno calimaqueo II no se dice nada del nacimiento de éste ni de la ayudantía prestada por Ártemis a Leto, y en el Himno calimaqueo IV, Apolo nace en esta isla con la ayuda de Ilitía.

52 Cf. p. e. Diod. 5.73.5; Aesch. Ag. 114-120, 135-137, 140-145. Con la breve alusión al mito de las Prétides, Calímaco da a entender la protección que brinda Ártemis a las jovencitas (233-236). En la mayoría de las versiones de dicha historia, quien salva de la locura a las hijas de Preto es Melampo, pero el poeta helenístico, tal vez al tratar de establecer una conexión entre el epíteto de Ártemis Hemera y la curación de aquéllas, hace que sea la diosa misma quien las libra de la locura. Otro dato importante que no aparece en la tradición común es que Calímaco hace que la diosa les de refugio a las Prétides, por lo que Preto funda el templo de Ártemis Coria. Para el mito de las Prétides, véase Apollod. 2.2.2; Hes. Fr. 131; Paus. 2.7.8; 8.18.7-8.

53 Cf. p. e. Aristoph. Lys. 645; Gimbutas 1991, pp. 230-231; Kirk 1992, p. 189; Frontisi Ducrox 2006, p. 153; Guettel 1998, pp. 34, 37; Downing 1999, p. 217; Vernant 2001, pp. 25, 27, 28, 40, 62 .

54 Así como Ártemis cuida y protege a la jóvenes y las prepara para, cuando les llegue la edad del matrimonio, entregarlas al cuidado de Hera, también se hace cargo de los jóvenes varones y de su preparación y sus ritos de iniciación mediante los cuales franquean la edad adulta, a la edad viril, cuando el efebo asume la situación de ciudadano-soldado (cf. Vernant 2001, pp. 25, 27, 28, 36). En esta esfera, la deidad es llamada

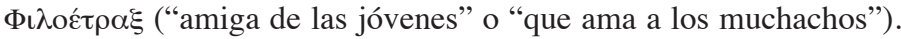


Diosa bondadosa, diosa terrible

En el himno, Calímaco, una vez que Ártemis ha alcanzado el grado de óv $\alpha \sigma \sigma \alpha / \tau o ́ \tau v \iota \alpha$, inicia una recopilación de ideas para dar las últimas pinceladas al retrato hímnico; así, presenta dos aspectos de la diosa, uno de abundancia y otro de carencia, ambos también asociados al ciclo vida-muerte.

En primera instancia, se advierte lo que sucede cuando ella está ausente: la peste ${ }^{55}$ acaba con los ganados, el invierno cae en las cosechas, mueren repentinamente los jóvenes y las madres y niños en el parto - si éstos logran nacer, lo hacen enfermos (vv. 119-128).

Continuando con el aspecto destructor de Ártemis, ella también castiga a los impíos e injustos, a quienes la deshonran, a quienes la olvidan, atentan contra sus lugares y cosas sagradas o se jactan de ser mejores cazadores que ella. Es por eso que Calímaco alude a dos mitos importantes, el primero, el del jabalí de Calidón (vv. 260-261). Eneo, rey de Calidón, se olvidó de mencionar a Ártemis en el ofrecimiento de las primicias de los frutos anuales de la región, por lo que la diosa, irritada, envió un jabalí enorme para que arrasara los sembrados, destruyera los rebaños y atacara a la población. ${ }^{56}$ El segundo mito tiene que ver con la hybris de Agamenón al jactarse de ser mejor arquero que ella (vv. 262-263). Ártemis, ya de antemano ofendida por la casa Atrida, aunó dicho insulto de Agamenón. En castigo, la diosa mandó vientos contrarios a la flota que había zarpado de Argos para retenerlos en Aúlide. La única manera de calmar su ánimo ofendido era el sacrificio de una doncella. ${ }^{57}$

En los dos mitos anteriores, el aspecto terrible de Ártemis o su venganza es completamente justo, pues los hombres deben ser respetuosos y piadosos con los dioses, venerarlos y no sentirse superiores a ellos. No deben ser soberbios, o serán justamente castigados. ${ }^{58}$

55 Cf. Paus. 7.9.2-3.

${ }^{56}$ Cf. Apollod. 1.8.2.

${ }^{57}$ Cf. Apollod. Epit. 2.11, 3.21-22; cf. Eur. IT 15-23; IA 87-92, 359-361; Soph. El. 564-575.

${ }^{58}$ Esto es algo que la misma Ártemis recuerda en el Hipólito de Eurípides (vv. 13391341): "Los dioses no se alegran de la muerte de los piadosos, pero a los malvados los destruimos con sus hijos y con sus casas" (traducción de José Luis Calvo Martínez). 
En su aspecto benéfico y propicio otorga buen ganado, favorece la siembra, hace crecer la fortuna, la muerte cae sólo sobre los viejos o los enfermos, se encarga de integrar a la familia alejando la discordia de las casas y compensa a quienes la obedecen y veneran como se debe (vv. $129-135) .{ }^{59}$

\section{Compañeras y seguidoras}

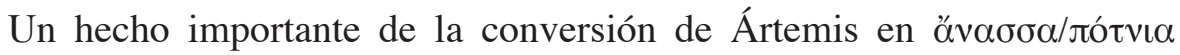
es la inclusión en su cortejo de algunas jóvenes mortales que se han consagrado a ella; sus seguidoras ya no serán únicamente las pequeñas Oceánides que obtuvo cuando niña. A partir de aquí, el himno revela la identidad de algunas de las ninfas o doncellas que acompañan a Ártemis o que son sus favoritas: por ejemplo, Cirene (vv. 206-208), Procris (vv. 209-210), Atalanta (vv. 215-224) y Britomartis, quien, según Calímaco,

${ }^{59}$ Diosa protectora del ganado: Esta prerrogativa es comparable a la de Hermes, dios de los pastores y los rebaños (cf. Apollod. 3.10.2; H. Hom. IV) y a la de Hécate, quien hace prosperar o menguar el ganado (cf. Hes. Th. 440-447).

Protectora de la siembra: Dominio que es también de Deméter, hija de Crono y Rea y deidad de la tierra cultivada, esencialmente del trigo, pues es quien enseña a los hombres a sembrar la tierra (cf. Apollod. 1.5.1).

Deidad que otorga fortuna: No he encontrado ninguna otra referencia que diga que este ámbito es propio de Ártemis.

Diosa de la concordia: Entra aquí en el ámbito hogareño, propiedad de Hestia. No he podido localizar alguna fuente que mencione a Ártemis como integradora de la familia. Respecto a los versos 133-135 del himno, algunos autores sostienen que probablemente Calímaco está haciendo referencia en ellos a una situación familiar de la corte de los Tolomeos: "Juntas, Arsínoe I y II, se ponían a la mesa; por tanto, Arsínoe I aún no había sido repudiada por Filadelfo, y Arsínoe II era esposa de Cerauno, medio hermano de Filadelfo. Nótese que Arsínoe I y Arsínoe II son, por una parte, esposas de hermanos, 'concuñas', y por otra, que Arsínoe I es 'cuñada' de Arsínoe II, ya que ésta era hermana de Filadelfo, esposo de aquélla" (cf. Tapia, nota 135 a la traducción de Call. H. III).

Diosa que recompensa la veneración y la obediencia: Por ejemplo, en el himno, Calímaco hace a Ártemis ofrecerle a los cíclopes alimentarlos con lo que ella cace si estos le fabrican un arco, flechas y carcaj (vv. 81-85). Recordemos también la suerte de Hipólito, joven favorito de la diosa y quien observaba piadosamente su culto y se mantenía virgen igual que ella (cf. Eur. Hipp.; Apollod. Epit. 1.18-19): Muere a causa de Afrodita sin que Ártemis lo pueda evitar, pero ésta, rogó a Asclepio que lo reviviera y lo transportó a Italia a su santuario de Aricia al borde del lago Nemi, donde se le conoce como Virbio (Ov. Met. 15.533-546; Verg. A. 7.765-780). 
es la ninfa predilecta de la diosa, por lo que habla prolijamente de ella y del mito de su nombramiento como Dictina (vv. 189-205). ${ }^{60}$

La mayoría de los mitos retomados o reinventados por Calímaco constatan que estas jóvenes tienen una relación directa o indirecta con el ejercicio de la caza, actividad regida por Ártemis, y con la virginidad. Se trata de mitos "reinventados" porque el poeta helenístico modifica los tópicos de la tradición mítica para cumplir con fines específicos, como cuando afirma que los héroes que participaron en la cacería de Calidón "no" le reprocharon a Atalanta que se llevara el premio, pues según la tradición no sucedió así: desde el inicio de la cacería, algunos se negaron a compartir la empresa con una mujer, y cuando la joven obtuvo el premio, otros se indignaron, pues no aceptaban que, habiendo varones, se le otorgara el premio a una mujer; ${ }^{61}$ o como cuando convierte a Cirene en uno de los ganadores de los juegos fúnebres en honor a Pelias, siendo que la tradición refiere que no participaron mujeres en tal torneo (Paus. 5.17.9) o que la única fue la ya mencionada Atalanta (Apollod. 3.9.2). Acaso tales modificaciones tienen nuevamente la intención de exaltar la figura femenina sobre la masculina.

Ahora bien, tomando en cuenta que Calímaco prefiere las características de la Atalanta arcadia y deja de lado las de la heroína beocia, ${ }^{62}$ y que no presenta a todas las jóvenes de las que se ha hablado en un orden de mayor a menor importancia o viceversa, sino que les da más peso a Britomartis y Atalanta, se puede afirmar que los atributos de éstas (virgen-

60 Para Procris, cf. Xen. Cyn. 9.18; para Atalanta, Apollod. 3.9.2; para Britomartis, Paus. 2.30.3; respecto a Dictina, epíteto utilizado para denominar también a Ártemis, Eur. Hipp. 145-151, 1130; IT 126. Véase también Aristoph. Ra. 1358. Sobre esto, algunos autores modernos mencionan que Britomartis y Dictina eran divinidades minoicas de la naturaleza, de la caza y del alumbramiento asimiladas a Ártemis, o que Dictina era simplemente su título en Creta (Rose 1973, p. 119; Hesiquio apud Ruipérez 1947, p. 33; Calvo, en Eur. Hipp., p. 15, n. 331, y en IT, p. 12, n. 358).

${ }^{61}$ Cf. Apollod. 1.8.2; Ov. Met. 8.432 ss.

62 Atalanta arcadia: Hija de Yaso, virgen, compañera de Ártemis, arquera, cazadora, luchadora que participa en la empresa de los argonautas y en la cacería calidonia, mata a Hileo y Reco, y está relacionada eróticamente con Meleagro (Apollod. 1.8.2, 1.8.6, 1.9.16, 3.9.2; Ov. Met. 8.318 ss., 10.564-572; Xen. Cyn. 13.18, 1.7; Prop. 1.1.9-16; Paus. 8.45.2).

Atalanta beocia: Hija de Esqueneo, virgen consagrada a Ártemis, corredora, relacionada con Hipómenes. Apollod. 1.8.2, 3.9.2; Paus. 8.35.10; Ov. Met. 10.560, 680; Hes. Fr. 73, 75, 76 . 
cazadora/cazadora-guerrera) se materializan en Ártemis para darle más

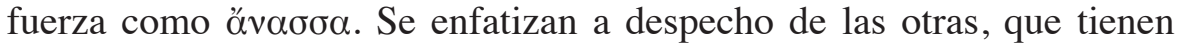
más de "esposa" que de virgen, guerrera o cazadora.

\section{Las amazonas y el culto en Éfeso}

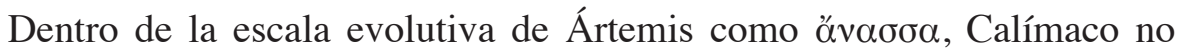
habla del poder de esta deidad en el ámbito del Peloponeso y sitios aledaños, sino que lo extiende a otras regiones, como, por ejemplo, la de los hiperbóreos y Oriente.

En dos ocasiones, el autor se refiere a Ártemis con el epíteto de Oủंus (vv. 204-240); por el contexto amazónico en el que el poeta hace la segunda mención, Opis era una diosa local de Éfeso (una Madre Tierra) vinculada o sustituida por Ártemis. Upis/Opis tiene como raíz ỏ denota abundancia; así, puede decirse que el culto de Ártemis efesia entra en relación con la tierra y, por lo tanto, con la fecundidad. ${ }^{63}$ Este aspecto relativo a la tierra, a la fertilidad y la abundancia se nota en su capacidad de influir en el parto y en la salud de los niños, de otorgar buen ganado, de favorecer las cosechas y de hacer crecer la fortuna.

Posteriormente, y sin olvidar este aspecto, Calímaco hace referencia a la fundación del culto de Ártemis en Éfeso por parte de las amazonas, el cual se extiende a Sardes y Berecintia (234-250). Como es bien sabido, la religión amazónica está dirigida a la guerra, pero también a la fertilidad. Es por ello que sus dioses principales (Ares, Cibeles y Ártemis) tienen características guerreras o de fecundidad. Ahora bien, recordemos que las amazonas "no son griegas", y por tanto sus dioses tampoco, es decir, son "bárbaros" y "salvajes". Por eso, la Ártemis de las amazonas, la Ártemis efesia, es concebida como una deidad guerrera (tal vez con el sobrenombre de Taurópola) ${ }^{64} \mathrm{y}$ de la fertilidad (bajo el nombre de Upis). 65

${ }^{63}$ Cf. Kirk 1992, p. 209.

${ }^{64}$ Cf. Tyrrell 1989, p. 114.

65 La Ártemis griega parecería no compartir esta prerrogativa, pues en la Ilíada ella hace evidente su desprecio por la guerra (21.485) y es representada como una niña torpe en ese dominio (21.476-495; 506-513); pero no hay que olvidar que Pausanias la describe ataviada con armas y escudo y en un contexto guerrero (4.13.1), o que los espartanos sacrificaban una cierva a Ártemis Agrótera antes de entrar en batalla (Burkert 2007, p. 205; Otto 1958, p. 71). Así, según Vernant (2001, pp. 29-30), la Ártemis griega, que 
Como diosa de la guerra, tiene la facultad de proteger una ciudad o un lugar en peligro de aniquilamiento, como cuando en el himno se hace referencia al momento en el que, los cimerios, bajo la dirección de un tal Ligdamis, intentaron destruir Éfeso (vv. 251-258) y fueron vencidos por las amazonas, protegidas por ella, antes de que llegaran a la ciudad. ${ }^{66}$

\section{Ártemis en el Olimpo}

La culminación que tiene Ártemis dentro del himno en su carácter de óv $\alpha \sigma \sigma \alpha$ es, junto con volverse diosa en Oriente, su ascensión al Olimpo para, por fin, ocupar el lugar que le corresponde entre los celícolas (vv. 140-148).

Veinte ninfas Amnisiadas se ocuparán de las sandalias y de los perros de la diosa cuando ésta no se dedique a la caza y se encuentre en el Olimpo (vv. 15-17). También se encargarán de alimentar y dar de beber a las ciervas que ella unce a su carro (vv. 162-167). El énfasis en la procedencia cretense de las ninfas, a mi juicio, refuerza el carácter de Gran Diosa de Ártemis.

Calímaco explica que sus ciervas son alimentadas, al igual que los caballos de Zeus, con trébol de la pradera de Hera (el jardín de las Hespérides). ${ }^{67} \mathrm{La}$ aseveración de que estos equinos comen trébol resulta extraña, pues los caballos de los dioses son, al igual que éstos, inmortales, por tanto, sería más lógico que los equinos de Zeus, y las ciervas de Ártemis, comieran ambrosía, el alimento de los dioses que proporciona inmortalidad, tal como lo hacen, por ejemplo, los caballos de Helios. ${ }^{68}$

no es propiamente la asiática, pero que procede de ella, sí interviene en ciertos aspectos de la guerra.

${ }^{66}$ La invasión cimeria a Éfeso (que tuvo lugar a comienzos del siglo VII a. C, según lo menciona Cuenca y Prado, en Calímaco, Himnos, p. 60, n. 62), no está documentada. Herodoto (1.15) atestigua que los cimerios, expulsados de sus tierras por los escitas, invadieron Sardes, pero no Éfeso Y por lo que respecta al nombre del dirigente que da Calímaco, la única referencia que he encontrado es Estrabón (1.3.21), quien dice que, efectivamente, los cimerios, bajo las órdenes de Ligdamis atacaron Sardes. Según Fernández Galiano, Ligdamis (1978, p. 401) era uno de los nombres de Dugdammê (Dugdammi, Tugdammê o Lygdamis), rey de los Ummân-Manda, tribu nómada cimeria.

${ }^{67}$ Cf. p. e. Hes. Th. 215-216, 275; Apollod. 2.5.11; Eur. Hipp. 743-751.

${ }^{68}$ Cf. p. e. Hom. Il. 5.341-342; Od. 5.92-96; Luc. Icar. 27; Apollod. Epit. 2.1; H. Hom. III; Ov. Met. 2.120. 
Pero parece que Calímaco aquí sigue la tradición de la Ilíada (5.369) en la que los caballos de Ares se alimentan en el Olimpo de pastura que los hace inmortales. También resulta peculiar la especificación del tipo de pastura de los caballos de la diosa: trébol, el cual, desde tiempos muy antiguos, es, en diversas mitologías y religiones, un símbolo ternario que hace referencia a la utilización de tríadas y que, cuando se relaciona con las divinidades, les adjudica un carácter triple, ya sea porque éstas poseen tres nombres, tres aspectos o han sido confundidas, asimiladas o evocadas (epíclesis) con otras deidades formando una tríada. ${ }^{69}$

Ahora bien, el hecho de que las ciervas de Ártemis coman trébol podría simbolizar para el autor y su público que tanto estos animales como su dueña participan del principio femenino de los ciclos de la vida y la luna. Ya que, debido a que el jardín de las Hespérides es símbolo de la inmortalidad y la vida, ${ }^{70}$ todo lo que brota allí puede tener el mismo atributo; así el trébol jugaría en este caso el mismo papel "inmortalizador" propio del néctar y la ambrosía. Por otro lado, pareciera que el poeta, al relacionar a estas ciervas con el trébol de la pradera de Hera, estuviera tratando de ligar íntimamente a las dos divinidades, pues Ártemis, como virgen y doncella, podía ser la contraparte de Hera tanto en el mito como en los ciclos biológicos, porque es patrona de las doncellas célibes y de los jovencitos (que en un futuro pasarán necesariamente al patronazgo de Hera), y Hera tiene a su cargo a las doncellas casaderas (que alguna vez estuvieron al cuidado de Ártemis). Con esto, puede interpretarse que la inclusión que hace Calímaco del símbolo del trébol en la relación Ártemis-Hera probablemente se refiere a que Ártemis forma parte (sustituyendo a Hebe) de la tríada de los ciclos de la vida.

Cuando por fin Ártemis se encuentra dentro del palacio de su padre, todos los dioses piden que se siente a su lado, pero ella prefiere tomar asiento junto a su hermano (vv. 168-169), tal vez para dejar claro que ostenta la misma jerarquía que él, y no simplemente porque puedan existir cier-

${ }^{69}$ Cf. Chevalier 1993; Graves 2001, p. 109; Otto 1958, p. 11. De este modo, quedaría justificada la asociación que Calímaco establece entre el trébol y la figura de Hera, pues ésta, dentro del culto sámico, es una divinidad de los ciclos de la vida y estacionales, por tanto una diosa triple que tiene tres aspectos o tres manifestaciones representadas en las tres hojas del trébol: Hera como niña (Hebe), como mujer madura casada (estío/verano y otoño), y anciana y viuda (invierno). Cf. Paus. 8.22.2; Rose 1973, p. 108.

${ }^{70}$ Cf. Eur. Hipp. 743-751; Rose 1973, p. 215. 
tos afectos fraternos. Todos los dioses la reclaman a su lado debido a que ahora se ha elevado en dignidad.

\section{Conclusiones}

En su Himno III, Calímaco traza la línea evolutiva en la que Ártemis

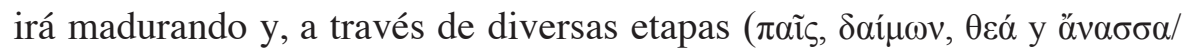

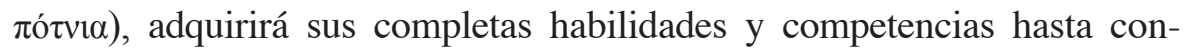
vertirse en una deidad no sólo del panteón olímpico, sino de otras partes del mundo conocido en ese entonces.

El poeta hace especial énfasis en el carácter infantil de la diosa, en su naturaleza virginal y salvaje, y en sus prerrogativas como partera, administradora de justicia, cazadora, guerrera y divinidad de los ciclos de la vida, la fertilidad y la abundancia.

Del intento que hace Calímaco por delinear la figura de esta deidad podemos concluir que nos presenta a varias Ártemis en una con preponderancia de la virgen cazadora, pues el autor mezcla elementos mitológicos y cultuales de la Ártemis arcadia, la táurica, la efesia y la cretense para tratar de dar una visión completa y homogénea.

Como arcadia, ella es diosa de ninfas y doncellas liberales, venerada sobre todo en aquella tierra agreste de Halas, Muniquio, Lusos, y relacionada principalmente con los montes Taigeto y Parrasio. De la Ártemis táurica, cuyo culto es propio de Escitia y algunos lugares del Peloponeso como Laconia y Halas, el poeta destaca su carácter sanguinario. De la efesia, retoma su prerrogativa como diosa de la fructificación y fecundación, asimilada a Upis, deidad de las amazonas en Asia. Finalmente, respecto a la Ártemis cretense, utiliza su aspecto de divinidad cazadora venerada en los montes.

Y de todo este sincretismo, el autor da preferencia a ciertas características míticas y cultuales por las que la Ártemis del Himno III, a pesar de tener múltiples prerrogativas y competencias, es predominantemente una virgen cazadora, diosa del mundo salvaje en todos sus aspectos y

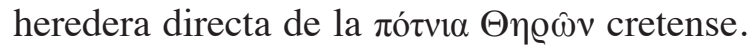




\section{BIBLIOGRAFÍA}

\section{Autores clásicos}

Apolodoro, Biblioteca, traducción de Margarita Rodríguez Sepúlveda, Madrid, Gredos, 1985.

APOLONIO DE RodAS, Argonáuticas, introducción, traducción y notas de Mariano Valverde Sánchez, Madrid, Gredos, 1996.

ARISTÓFANES, Las once comedias, introducción y traducción de Ángel Ma. Garibay, México, Porrúa, 2001 (“Sepan cuantos...”).

ARISTOPHANES, Birds, Lysistrata, Women at the Thesmophorian, edición y traducción de Jeffrey Henderson, Cambridge-Massachusetts, Harvard University Press, 2000 (The Loeb Classical Library).

-, The Peace, The Birds, The Frogs, traducción de Benjamin Bickley Rogers, Cambridge, Massachusetts, Harvard University Press, 1924 (The Loeb Classical Library).

ARISTÓTELES, Investigación sobre los animales, introducción de Carlos García Gual, traducción y notas de Julio Pallí Bonet, Madrid, Gredos, 1992.

Calímaco, Himnos, Epigramas y fragmentos, traducción de Luis Alberto de Cuenca y Prado y Máximo Brioso Sánchez, Madrid, Gredos, 1980.

-, Himnos y epigramas, traducción de Pedro C. Tapia Zúñiga, México, Universidad Nacional Autónoma de México, 1984 (Bibliotheca Scriptorum Graecorum et Romanorum Mexicana).

—, Himnos, introducción, traducción y notas de María Elena del Río y Ma. Teresa Forero de Asman, Madrid, Aguilar, 1972.

Callimachos, Aetia, Iambi, Lyric Poems, Hecale, Minor Epic and Elegiac Poems, edición, traducción y notas de C. A. Trypanis, Cambridge-Massachusetts, Harvard University Press, 1958 (The Loeb Classical Library).

-, Hymns and Epigrams, traducción de A. W. Mair, Cambridge-Massachusetts, Harvard University Press, 1921 (The Loeb Classical Library).

Claudio Eliano, Historia de los animales, introducción, traducción y notas de José María Díaz-Regañón López, Madrid, Gredos, 2001.

EsQuilo, Tragedias, introducción de Manuel Fernández-Galiano, traducción y notas de Bernardo Perea Morales, Madrid, Gredos, 1993.

EURíPIDES, Tragedias I, introducción, traducción y notas de Alberto Medina González y Juan A. López Férez, Madrid, Gredos, 1977.

-, Tragedias II, introducción, traducción y notas de José Luis Calvo Martínez, Madrid, Gredos, 1978.

-, Tragedias III, introducción, traducción y notas de Juan Miguel Labiano, Madrid, Cátedra, 2005.

Hesíodo, Obras y fragmentos, introducción, traducción y notas de Aurelio Pérez Jiménez y Alfonso Martínez Diez, Madrid, Gredos, 1997. 
—, Teogonía, traducción de Paola Vianello de Córdoba, México, Universidad Nacional Autónoma de México, 1986 (Bibliotheca Scriptorum Graecorum et Romanorum Mexicana).

Himnos homéricos. La batracomiomaquia, traducción, introducción y notas de Alberto Bernabé Pajares, Madrid, Gredos, 1978.

Himnos órficos, introducción, traducción y notas de Miguel Periago Lorente, Madrid, Gredos, 1987.

HOMER, The Odyssey, traducción de A. T. Murray, Cambridge-Massachusetts, Harvard University Press, 1919 (The Loeb Classical Library).

Homero, Ilíada, traducción de Emilio Crespo Güemes, Madrid, Gredos, 1991.

_, Odisea, traducción de José Luis Calvo, Madrid, Cátedra, 2001.

-, Odisea, introducción de Manuel Fernández-Galiano, traducción de José Manuel Pabón, Madrid, Gredos, 1998.

LuCIANo, Obras III, traducción y notas de Juan Zaragoza Botella, Madrid, Gredos, 1990.

Pausanias, Descripción de Grecia, introducción, traducción y notas de María Cruz Herrero Ingelmo, Madrid, Gredos, 1994.

Sófocles, Tragedias, introducción de José S. Lasso de la Vega, traducción y notas de Assela Alamillo, Madrid, Gredos, 1992.

\section{Autores modernos}

BoARDMAN, John, Athenian Black Figure Vases: A Handbook, London, Thames and Hudson, 1974.

Bonavides Mateos, Enrique, "Artemisa/Diana o el enigma de los límites", Acta Poetica, 17, primavera, 1995, pp. 211-222.

BURKERT, Walter, Religión griega arcaica y clásica, traducción de Helena Bernabé, Madrid, Abada, 2007.

Chevalier, Jean, Diccionario de los símbolos, Barcelona, Herder, 1993.

DownING, Christine, La Diosa, imágenes mitológicas de lo femenino, Barcelona, Kairós, 1999.

Duby, George, Historia de las mujeres en Occidente, tomo I, Madrid, Altea / Taurus / Alfaguara, 1991.

E-canina: http://www.e-canina.com.ar.

Fernández Galiano, Emilio, Léxico de los Himnos de Calímaco, tomo III, Madrid, Consejo Superior de Investigaciones Científicas, 1978.

Frontisi Ducroux, Françoise, El hombre-ciervo y la mujer-araña. Figuras griegas de la metamorfosis, Madrid, Abada, 2006.

Gimbutas, Marija Alseikaite, Dioses y diosas de la vieja Europa (7000-3500 a. C). Leyendas e imaginería, Madrid, Ediciones Istmo, 1991.

-, The Language of the Goddess, Londres, Thames \& Hudson, 2001.

GonZÁlez SERrano, Pilar, "Consideraciones iconográficas sobre la Ártemis efesia”, en Actas del I Congreso Español del Antiguo oriente Próximo: El Medite- 
rráneo en la antigüedad: Oriente y Occidente, CSIC, 1997, p. versión en línea: http://www. labherm.filol.csic.es

Graves, Robert, Los mitos griegos 1, México, Alianza, 2001.

"Greek Dog Breeds", en DogBreeds.net:www.dogbreeds.net/greek-dogs.html.

Grimal, Pierre, Diccionario de mitología griega y romana, Barcelona, Paidós, 1981.

Guettel Cole, Susan, "Domesticating Artemis", en The Sacred and the Femine in Ancient Greece, London-New York, Routledge, 1998, pp. 27-43.

KeréNYI, Karl, Los dioses de los griegos, Caracas, Monte Ávila, 1997 (Serie Ideas). KIRK, G. S., El mito. Su significado y funciones en la antigüedad y en otras culturas, Barcelona, Paidós, 1985.

—, La naturaleza de los mitos griegos, Barcelona, Labor, 1992.

LidDELL, Henry George, and Robert ScotT (comps.), Greek English Lexicon, Oxford, Oxford University Press, 1940.

Отто, Walter Friedrich, Los dioses de Grecia. La imagen de lo divino a la luz del espíritu griego, Buenos Aires, EUDEBA, 1958.

Pomeroy B., Sara, Diosas, rameras, esposas y esclavas. Mujeres en la antigüedad clásica, Madrid, Akal, 1990.

Quezada SAnZ, Fernando, "Carros en el antiguo Mediterráneo: de los orígenes a Roma", en VV. AA., Historia del carruaje en España, Madrid, Cinterco, 2005, pp. 16-71.

Rodríguez Maldonado, Marysol Alhim, Imagen de Ártemis en el Himno III de Calímaco, tesis de licenciatura en Letras Clásicas, México, Universidad Nacional Autónoma de México, 2010 (inédita).

Rose, H. J., Mitología griega, Barcelona, Labor, 1973.

RUIPÉREZ, M. S., “Ártemis, divinidad dorioiliria. Etimología y expansión”, Emérita, XV, 1947, pp. 1-60.

RUIZ DE Elvira, Antonio, Mitología clásica, Madrid, Gredos, 1982.

TaPia ZÚÑIGa, Pedro Constantino, "Diana Lucina (un problema de Calímaco)", Nova Tellus, 9-10, 1991-1992, pp. 9-20.

Tyrrell Blake, William, Las amazonas. Un estudio de los mitos atenienses, México, FCE, 1989.

Vernant, Jean-Pierre, La muerte en los ojos. Figuras del otro en la antigua Grecia, Barcelona, Gedisa, 2001.

_, Mito y religión en la Grecia antigua, Barcelona, Ariel, 1991.

VILLARD, François, Les Vases grecs, Paris, Presse Universitaire de France, 1956. 